\title{
Mobile Radio Streaming Application Using Networked Radio System as a Media Convergence Collaboration Movement for Ponorogo Radio Discussion Forum
}

\section{Aplikasi Mobile Radio Streaming Menggunakan Sistem Radio Berjaringan Sebagai Gerakan Kolaborasi Konvergensi Media Untuk Forum Diskusi Radio Ponorogo}

\author{
Mochammad Iqbal Pristiyo $^{1}$, Dihin Muriyatmoko ${ }^{2}$, Nur Aini Shofiya Asy'ari ${ }^{3}$ \\ \{iqbalpristiyo@mhs.unida.gontor.ac.id ${ }^{1}$,dihin@unida.gontor.ac.id ${ }^{2}$, nurainishofia@unida.gontor.ac.id $\left.{ }^{3}\right\}$
}

Universitas Darussalam Gontor

\begin{abstract}
The development of streaming radio has been very developed, radio in digital form is also known as internet radio because to access streaming radio you must use the internet media. However, there are several radio stations in Ponorogo that still use conventional radio whose coverage is limited because they use an antenna to reach the signal range, and can only reach local areas because Ponorogo has several highlands and several mountains. This study aims to create a Networked Streaming Radio application so that Ponorogo radio station broadcasts can reach any place that has an internet connection and can accommodate the Ponorogo radio station industry which still does not have an Android-based streaming radio as a media convergence collaboration movement for the Ponorogo radio discussion forum. This research uses the waterfall which consists of five stages, namely: identification, design, implementation, verification, maintenance. Testing this streaming radio application using the black box method shows the application is running well and there are no errors. Testing using 6 different media and resolutions was carried out to find out whether the Ponorogo Radio application could run well on various media/smartphones and different resolutions.
\end{abstract}

Keywords - Android; Mobile application; Online Radio; Radio Streaming

\begin{abstract}
Abstrak. Perkembangan media radio streaming saat ini menunjukkan kemajuan. Dari radio yang berbentuk analog menjadi digital atau bisa disebut radio internet karena untuk mengakses siaran harus memanfaatkan media internet. Namun terdapat beberapa stasiun radio di Ponorogo yang masih menggunakan radio terestrial yang daya jangkauan terbatas karena masih memanfaatkan antena manual untuk mencapai jangkaun sinyal, dan hanya bisa menjangkau area local saja, dikarenakan Ponorogo memiliki beberapa daratan tinggi dan beberapa gunung. Penelitian ini bertujuan untuk membuat sebuah aplikasi Radio Streaming Berjaringan, agar siaran stasiun radio Ponorogo dapat menjangkau setiap tempat yang terdapat koneksi internet dan dapat menampung industry stasiun radio Ponorogo yang masih belum mempunyai radio streaming bebrbasis android sebagai gerakan kolaborasi konvergensi media untuk forum diskusi radio Ponorogo. Penelitian ini menggunankan metode waterfall yang terdapat 5 tahapan yaitu : identifikasi, desain, implementasi, verifikasi, maintenance. Pengujian aplikasi radio streaming ini menggunakan metode black box menunjukan aplikasi berjalan dengan baik dan tidak ada kesalahan. Pengujian dengan menggunakan 6 buah media dan resolusi yang berbeda dilakukan untuk mengetahui apakah aplikasi Radio Ponorogo ini dapat berjalan dengan baik pada berbagai media/smartphone dan resolusi yang berbeda.
\end{abstract}

Kata Kunci - Android; Mobile application; Radio Online; Radio Streaming

\section{Pendahuluan}

Perubahan media informasi yang sangat cepat membutuhkan tindakan yang cepat pula, terutama untuk media konvensional misalnya industri radio. Walaupun radio mempunyai beberapa kelebihan misalnya jangkauan luas dan dapat menembus ruang dan waktu, radio juga mempunyai kekurangan yang harus ditindaklanjuti dengan cara inovasi. Radio memiliki sifat auditori untuk bisa didengar oleh pendengar. Pesan siaran radio gampang hilang dari ingatan otak pendengar, dan belum bisa diulang. Maknanya pesan siaran radio sifatnya sekilas, tidak detil dan rinci. Siaran radio juga memiliki banyak gangguan yang teknis. Karena kekuatan sinyal radio adalah suara atau bunyi, maka unsur ini juga yang dapat menjadi kekurangan disebabkan sinyal yang terganggu, suara menjadi menghilang atau muncul noise [1].

Makin canggih media atau alat informasi, sedangkan radio sudah mulai ditinggalkan pendengar, maka sekarang ini usaha siaran radio sudah tak lagi diminati. Saingan siaran radio bukan saja televisi tapi juga media situs online yang kecepatannya jauh mengalahkan siaran radio. Bahkan, jejaring sosial bisa menjadi pilihan warga untuk berbagi berbagaimacam informasi. Di tengah transformasi media yang ramai saat ini, industri radio berada dalam situasi yang sulit. Dari informasi media warga yang dirilis oleh Nielsen memperlihatkan bahwa tren mendengarkan radio warga 
terus menurun bahkan pada 2015 berada diangka 15,77\%, berbanding terbalik dengan media internet yang mampu menembus diangka $37.845 \%$. Kehadiran media internet juga terus menggerus penghasilan iklan radio. Karenanya, dalam menghadapi situasi media baru yang serba digital tersebut maka radio harus bertransformasi dan berkonvergensi dengan media baru. Kesadaran para pengelolah radio di Ponorogo bahwa dalam usaha bertahan di zaman digital ini tidak bisa dilaksanakan secara sendiri-sendiri. Meski tiap radio harus berkompetisi tetapi mereka sadar bahwa saat ini industri radio kurang bisa memberikan penghasilan kehidupan pada masa depan jika saling peduli secara bersama sama, Maka dari itu penelitian ini bertujuan untuk membangun gerakan kolaborasi konvergensi media untuk forum diskusi radio Ponorogo [2] dan membantu industri radio yang masih belum memiliki radio streaming berbasis mobile. Desain awal penelitian ini sudah dibuat dalam penelitian sebelumnya yang menggunakan metode mindmap [3]. Pada awalnya penelitian ini dimulai dari tahun 2019 yang memberikan bimbingan dan penyuluhan kepada radio Songgolangit di Kabupaten Ponorogo [4]. Dalam penelitian tersebut juga sudah diujikan sebuah aplikasi radio streaming yang berbasis android. Hingga saat ini semua masyarakat yang terhubung dengan intenet bisa menikmati siaran tersebut via HP android mereka [5].

\section{METODE}

Metode Rancangan Sistem pada aplikasi Radio Ponorogo ini menggunakan Metode Waterfall. Ada lima tahapan utama dalam Metode Waterfall yaitu : identifikasi, desain, implementasi, verifikasi, maintenance. Disebut waterfall yang memiliki makna air terjun disebabkan diagram tahap prosesnya mirip dengan air terjun yang memiliki tingkat. Tahapan dalam Metode Waterfall disajikan pada Gambar 1 [6].

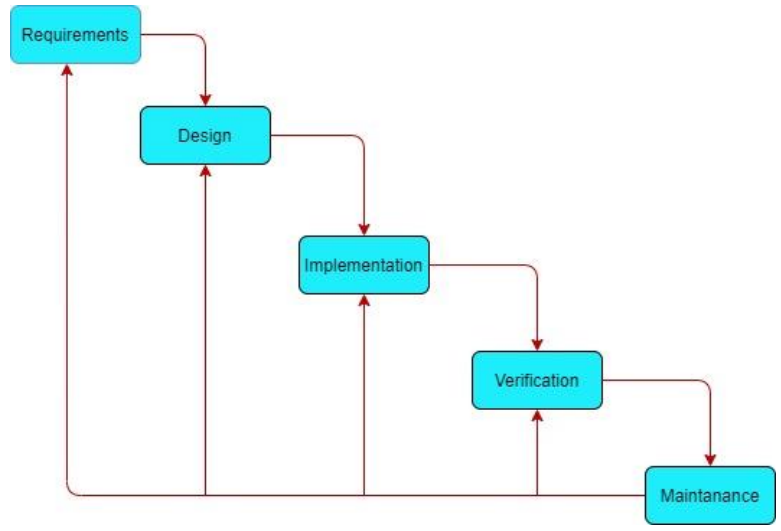

\section{A. Identifikasi}

Gambar 1. Metode Waterfall [6]

Tahap identifikasi dilaksanakan untuk menentukan apakah kejadian dari suatu masalah pada aplikasi mobile yang dikembangkan. Dalam tahapan ini proses pengumpulan data yang dibutuhkan guna melaksanakan penelitian adalah dengan menggunakan metode pengumpulan data atau metode untuk mendapatkan informasi yang dibutuhkan untuk mencapai tujuan riset. Berikut kebutuhan penelitian yang diperlukan seperti terlihat pada Tabel 1.

Tabel 1. Kebutuhan dan Identifikasi Penelitian

\begin{tabular}{ccl}
\hline No & \multicolumn{1}{c}{ Kegiatan } & \multicolumn{1}{c}{ Hasil } \\
\hline 1 & Identifikasi Masalah & $\begin{array}{l}\text { Terdapat beberapa stasiun radio yang masih belum mempunyai } \\
\text { aplikasi radio streaming berbasis mobile }\end{array}$ \\
\hline \multirow{2}{*}{2} & Konten/isi dari aplikasi & $\begin{array}{l}\text { Pengelompokan stasiun radio ponorogo yaitu radio Suara } \\
\text { Gontor, radio Songgolangit, radio Romansa, radio } \\
\text { Dutanusantara. }\end{array}$ \\
\hline 3 & Solusi yang ditawarkan & $\begin{array}{l}\text { Membangun aplikasi Radio Ponorogo sebagai gerakan } \\
\text { kolaborasi konvergensi media untuk forum diskusi radio - radio } \\
\text { di ponorogo }\end{array}$ \\
\hline 4 & Teknologi yang digunakan & Bahasa pemograman Android Studio 4.0 \\
\hline
\end{tabular}

\section{B. Desain sistem}

Fase ini adalah pembuatan desain berdasarkan pada kebutuhan perangkat lunak untuk di implementasikan. Tahap desain memiliki tujuan untuk menentukan spesifikasi komponen sistem informasi yang cocok dengan tahap analisis. 
Procedia of Engineering and Life Science Vol.1 No. 1 March 2021

Seminar Nasional \& Call for Paper Fakultas Sains dan Teknologi (SENASAINS $1^{\text {st }}$ ) Universitas Muhammadiyah Sidoarjo

Use Case Diagram adalah gambaran skenario interaksi antara sistem dan pengguna. Sebuah diagram use case menjelaskan hubungan antara aktor dan aktifitas actor yang dapat dikerjakannya pada aplikasi. Berikut ini merupakan gambaran use case diagram pengguna aplikasi Radio Ponorogo pada Gambar 2 di bawah.

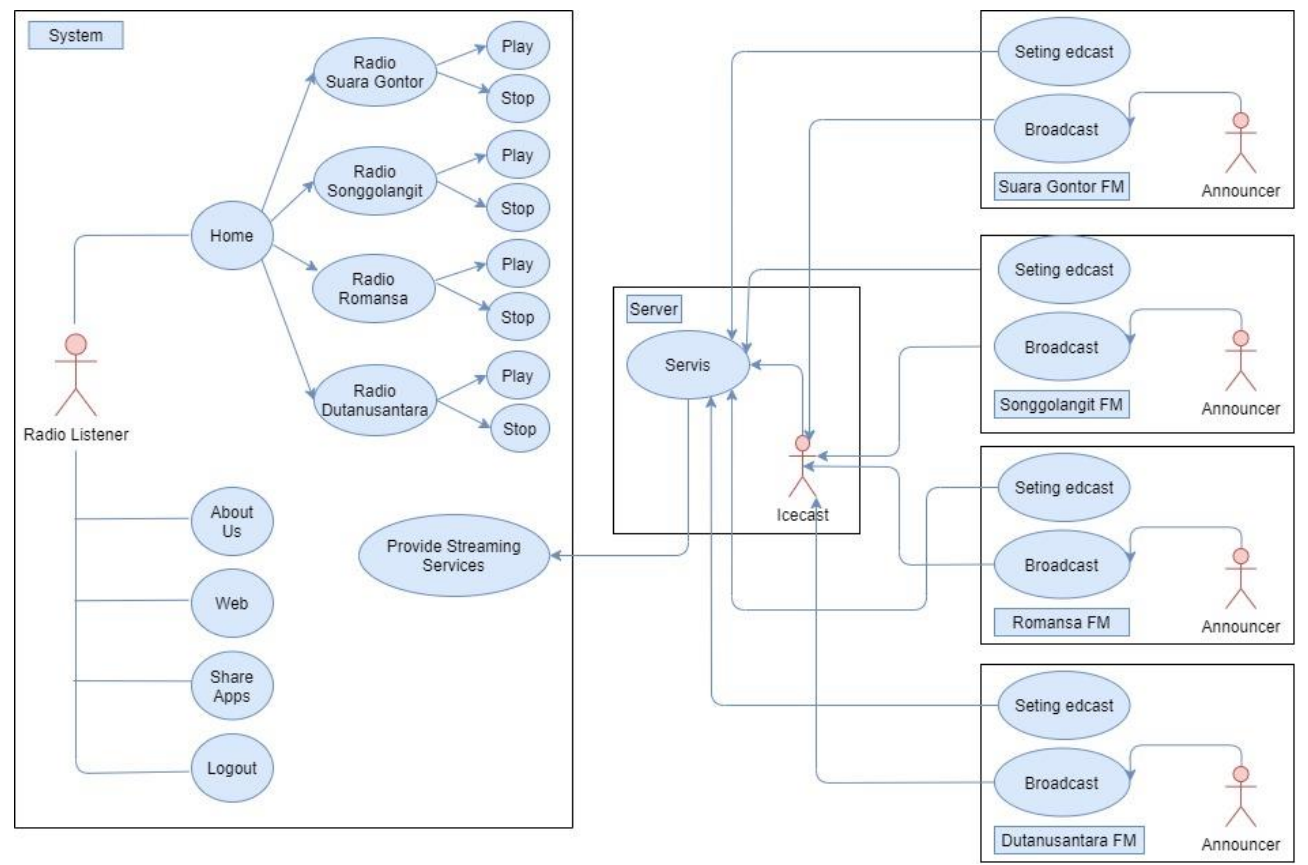

Gambar 2. Use Case Diagram Pengguna Aplikasi Radio Ponorogo

Alur proses aplikasi digambarkan dengan Activity Diagram agar memudahkan tahapan implementasi aplikasi. Berikut Activity Diagram aplikasi yang akan dibangun tertera pada Gambar 3.

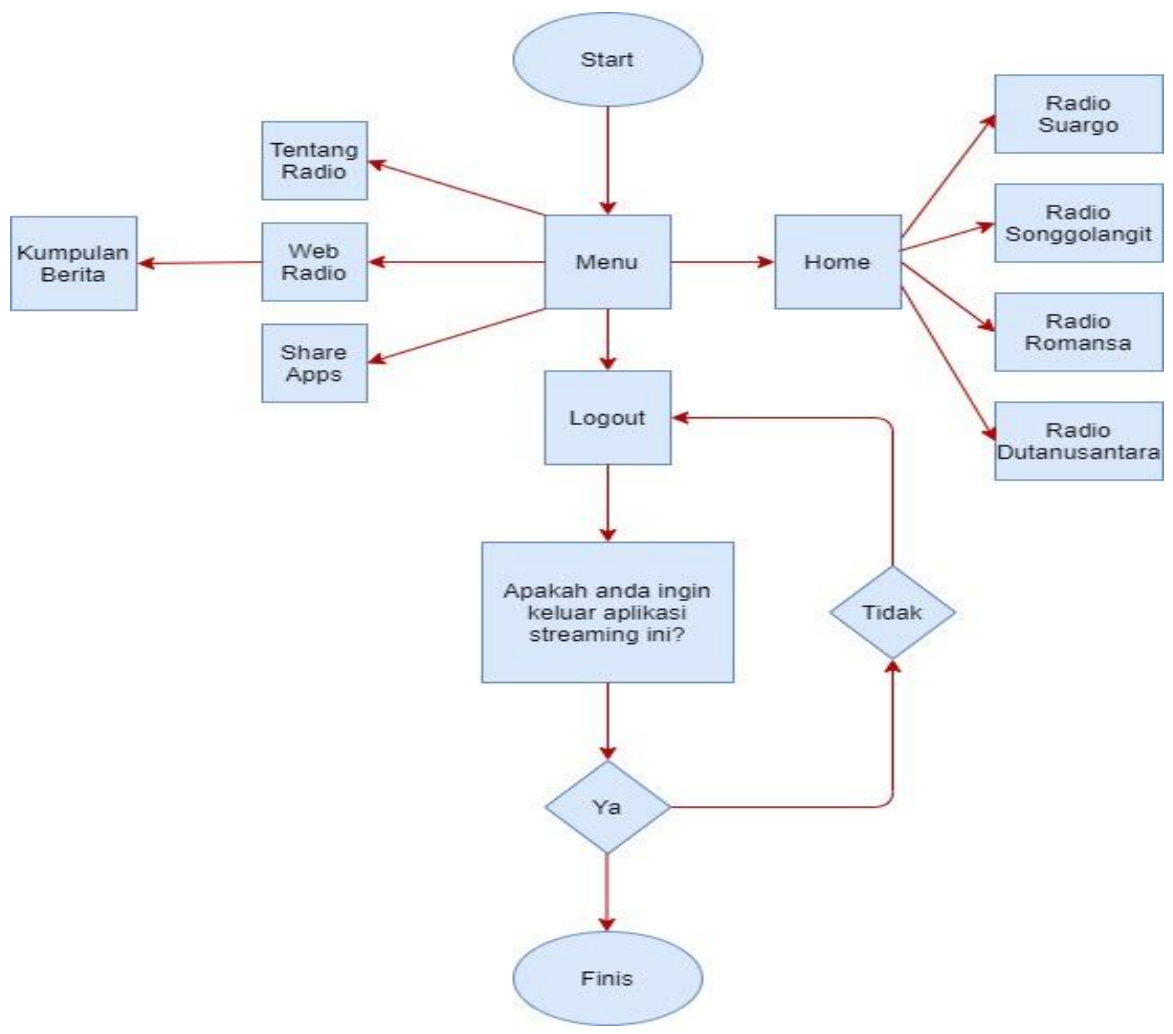

Gambar 3. Activity Diagram Alur Proses Aplikasi Radio Streaming 


\section{Implementasi}

Tahap implementasi pada penelitian ini dilakukan dengan 2 pengujian yaitu pengujian dengan metode black box, pengujian dengan menggunakan 5 buah media dengan resolusi yang berbeda dan terakhir pengujian terhadap pengguna umum playstore. Pengujian aplikasi dengan menggunakan metode black box dilakukan untuk menguji apakah menu dan fitur yang ada dalam aplikasi tersebut berjalan lancar dan tidak terdapat error. Pengujian dengan menggunakan 6 buah media dan resolusi yang berbeda dilakukan untuk mengetahui apakah aplikasi Radio Ponorogo ini dapat berjalan dengan baik pada berbagai media/smartphone dan resolusi yang berbeda. Implementasi ini juga dilaksanakan langsung di Forum Diskusi Radio Ponorogo [3].

\section{Verifikasi}

Tahap vertifikasi pada penelitian ini dibuktikan dengan aplikasi yang telah diupload pada 9 september 2020 dan dapat didownload di google playstore berikut ini link aplikasinya https://play.google.com/store/apps/details?id=com.amoled.radiosaya [7] dan juga dapat diketikan langsung pada kolom pencarian dengan keyword "Radio Ponorogo".

\section{E. Penerapan program dan pemeliharaan}

Tahap pemeliharaan (maintenance) telah di lakukan pada hari ahad tanggal 7 maret 2021 dengan 1.1 dan perbaikan dilakukan untuk eror yang ada pada versi sebelumnya yaitu versi 1.0 serta perbaikan dari segi user interface.

\section{HaSil dan Pembahasan}

Berdasarkan tahapan-tahapan yang dilakukan pada saat Analisa dan perancangan system maka dalam tahapan selanjutya yaitu tahapan implementasi diperoleh hasil Aplikasi Radio Ponorogo yang berfungsi untuk membantu stasiun radio - radio di Ponorogo yang hanya dapat siaran dengan jangkauan terbatas atau area lokal saja dan membantu bagi yang masih belum mempunyai radio streaming berbasih mobile dapat bergabung sebagai gerakan kolaborasi konvergensi media untuk forum diskusi radio Ponorogo. Berikut adalah interface atau tampilan dari aplikasi Radio Ponorogo seperti pada Gambar 4:

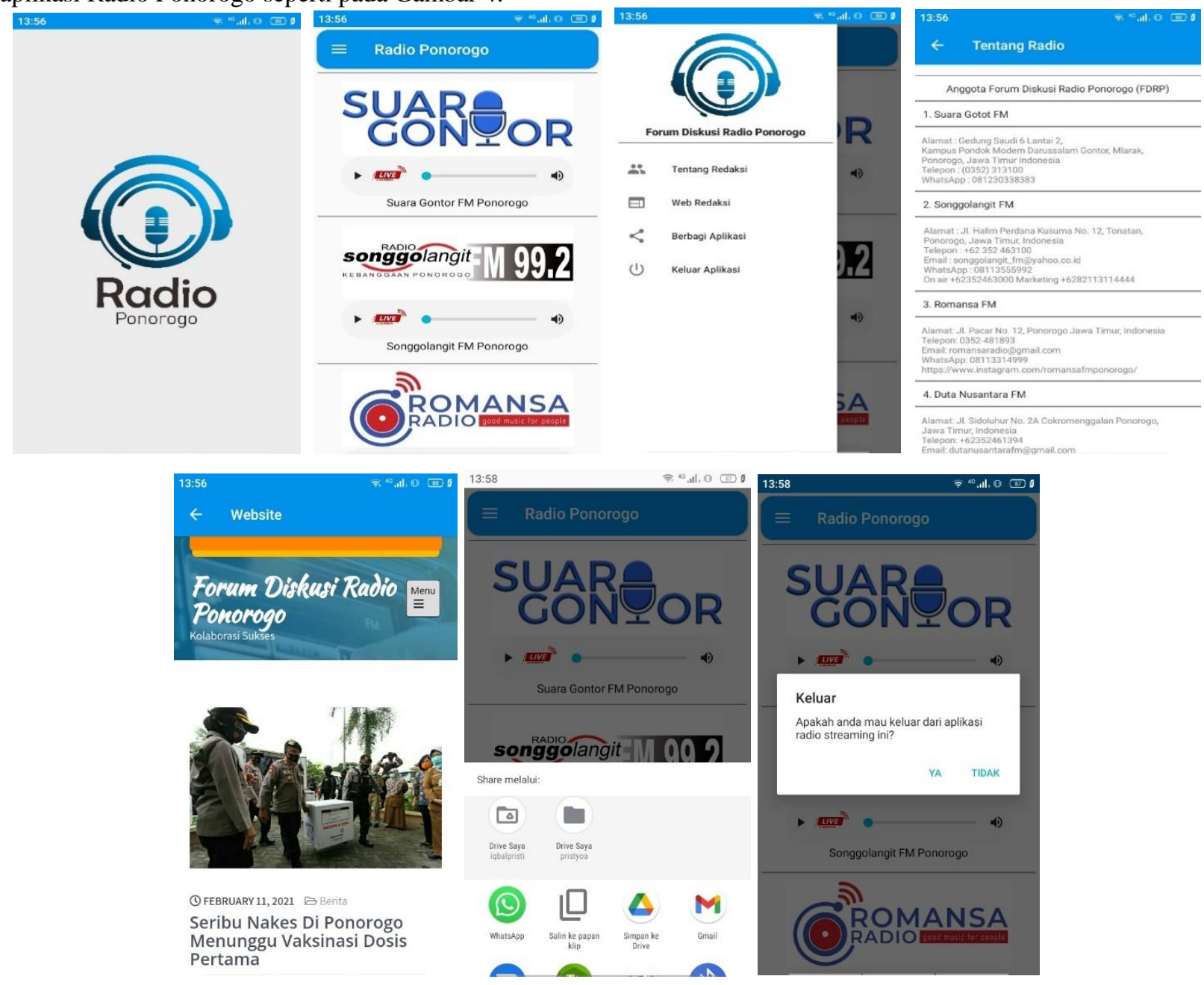


Procedia of Engineering and Life Science Vol.1 No. 1 March 2021

Seminar Nasional \& Call for Paper Fakultas Sains dan Teknologi (SENASAINS $1^{\text {st }}$ ) Universitas Muhammadiyah Sidoarjo

Gambar 4. Interface Radio Ponorogo

Aplikasi radio streaming ini mirip dengan aplikasi yang sudah pernah ada diantaranya radio berjaringan komunitas islam di Kabupaten Tulungagung [8] dan radio komunitas untuk sarana mitigasi bencana pada Gunung Kelud [9]

Aplikasi yang telah dirancang dan dibangun perlu diuji coba melalui beberapa proses. Pengujian aplikasi Radio Ponorogo diutamakan pada pengujian funsional, maka metode pengujian yang digunakan adalah Black Box Testing[10].

Berikut adalah rekapan hasil pengujian blackbox terhadap menu-menu atau fitur-fitur yang ada dan dikembangkan dalam aplikasi Radio Ponorogo ini.

Tabel 2. Rekap hasil pengujian aplikasi Radio Ponorogo dengan Blackbox

\begin{tabular}{cclc}
\hline No & Menu & \multicolumn{1}{c}{ Proses dan Hasil } & Keterangan \\
\hline 1 & Welcome Screen & Merupakan tampilan pembuka yang berisikan logo aplikasi. & Berhasil \\
\hline & Home & Songgolangit, Radio Duta Nusantara, Radio Suara Gontor & Berhasil \\
& & yang dapat di putar dan diberhentikan. & Berhasil \\
\hline 3 & Navigation Menu & Di menu Navigation Drawer pengguna dapat mengetahui & Berhasil \\
\hline 4 & Web & Menu untuk ke alamat website radio ponorogo & Berhasil \\
\hline 5 & Share & Menu untuk berbagi aplikasi & Berhasil \\
\hline 6 & Logout & Menu untuk keluar aplikasi radio streaming ini & \\
\hline
\end{tabular}

Berdasarkan hasil uji coba yang sudah dilaksanakan, aplikasi Radio Ponorogo ini telah memenuhi standar untuk tujuan yang ditentukan. Uji fungsionalitas pada setiap menu ataupun fiturnya memperlihatkan hasil yang memuaskan. Dari sisi lain aplikasi ini telah sesuai perancangan dan perencanaan. Dengan demikian dapat dikatakan bahwa sistem dari aplikasi Radio Ponorogo ini bekerja dengan baik dan dapat digunakan cocok dengn fungsinya. Pengujian yang telah dilakuka menggunakan enam buah media handphone atau smartphone untuk mencoba apakah aplikasi radio ini betul-betul dapat dijalankan dengan sistem operasi Android, media tersebut diantaranya adalah:

Tabel 3. Hardware Android Media Pengujian

\begin{tabular}{lllll}
\hline No & Jenis Handphone & Versi Android & Ukuran Layar & Keterangan \\
\hline 1 & OPPO A31 & Pie (9.0) & 6,5 Inches & Berhasil \\
2 & OPPO F7 & Oreo (8.1) & 6,23 Inches & Berhasil \\
3 & Realmi 5 Pro & Pie (9.0) & 6,3 Inches & Berhasil \\
4 & Advan Nasa 5202 & Pie (9.0) & 5,2 Inches & Berhasil \\
5 & Xiaomi Redmi Note 8 & Pie (9.0) & 6,3 Inches & Berhasil \\
6 & OPPO F3 & Noughat (7.1) & 5,5 Inches & Berhasil \\
\hline
\end{tabular}

\section{KESIMPULAN}

Uji blackbox menunjukkan bahwa aplikasi radio ini bisa berjalan lancar dan tanpa error. Uji smartphone dengan enam HP android berbagai merek dan ukuran layar memperlihatkan aplikasi dapat berjalan dengan baik untuk smartphone yang memiliki ukuran minimal 4.1 inchi dan sistem operasi Android 5.1 (Lolipop). Pengguna dapat mengakses aplikasi Radio Ponorogo di berbagai tempat dengan syarat terhubung dengan koneksi internet. Diusianya yang masih muda, Forum Diskusi Radio Ponorogo (FDRP) bisa menggandeng empat radio di area Ponorogo untuk bergabung yakni radio Songgolangit Ponorogo, radio Romansa Ponorogo, radio Suara Gontor dan radio Duta Nusantara.

\section{REFERENSI}

[1] N. A. S. Asy'ari and M. Luthfi, "Analisis Penerapan Konvergensi Media Pada Usaha Penyiaran Radio Di 
Procedia of Engineering and Life Science Vol.1 No. 1 March 2021

Seminar Nasional \& Call for Paper Fakultas Sains dan Teknologi (SENASAINS $1^{\text {st }}$ ) Universitas Muhammadiyah Sidoarjo

Ponorogo," Perspekt. Komun., vol. 1, no. 2, 2018, [Online]. Available: https://jurnal.umj.ac.id/index.php/perspektif/article/view/3892.

[2] "Forum Diskusi Radio Ponorogo - Kolaborasi Sukses." http://radioponorogo.org/ (accessed Aug. 22, 2020).

[3] N. A. S. Asy'ari and D. Muriyatmoko, "FASILITASI RADIO STREAMING BERJARINGAN SEBAGAI GERAKAN KOLEKTIF KONVERGENSI MEDIA Nur,” BERNAS J. Pengabdi. Kpd. Masy., vol. 2, no. 2, Jun. 2021, doi: 10.31949/jb.v2i2.754.

[4] D. Muriyatmoko, N. A. S. Asy'ari, and M. S. Arif, “Android Radio Streaming Apps for Songgolangit FM Ponorogo," in Journal of Physics: Conference Series, 2019, vol. 1381, no. 1, p. 12017.

[5] N. A. S. Asy'Ari and D. Muriyatmoko, "Usability Testing for Android Radio Streaming Apps of Songgolangit FM,” J. Phys. Conf. Ser., vol. 1471, no. 1, 2020, doi: 10.1088/1742-6596/1471/1/012011.

[6] I. Sommerville, Software Engineering, 9th ed. USA: Addison-Wesley Publishing Company, 2010.

[7] "Radio Ponorogo - Apps on Google Play," Radio Ponorogo, 2021. https://play.google.com/store/apps/details?id=com.amoled.radiosaya (accessed Aug. 10, 2021).

[8] R. Panuju, "Strategi Berjaringan Radio Komunitas Islam Madu FM Tulungagung," J. Sosiol. Reflektif, vol. 12, no. 2, p. 289, Apr. 2018, doi: 10.14421/jsr.v12i2.1320.

[9] A. M. Huda, "Model Strategi Pengembangan Sosial Radio Komunitas dalam Mitigasi Bencana Di Kawasan Gunung Kelud," Aristo, vol. 7, no. 2, p. 277, 2019, doi: 10.24269/ars.v7i2.1749.

[10] U. Hanifah, R. Alit, and S. Sugiarto, "Penggunaan Metode Black Box Pada Pengujian Sistem Informasi Surat Keluar Masuk," SCAN - J. Teknol. Inf. dan Komun., vol. 11, no. 2, pp. 33-40, 2016. 